Первый МГМУ им. И.М. Сеченова Минздрава России, Москва, Россия (Сеченовский университет)

И.В. Нестерова, Е.О. Халтурина, Г.А. Чудилова,

С.В. Ковалева, Н.В. Гарскова

\title{
Врожденные и
} приобретенные интерферонопатии

Учебно-методическое пособие

Москва, 2020 год 
Рекомендовано к изданию Ученым советом АПО ФГБУ ФНКЦ ФМБА России. Протокол № 320 от 23 октября 2020 г.

\section{Авторы учебно-методического пособия:}

Нестерова Ирина Вадимовна-доктор медицинских наук, профессор кафедры иммунопатологии и иммунодиагностики ФГБУ ФНКЦ ФМБА России (зав. кафедрой доктор медицинских наук, профессор Маркова Т.П.)

Халтурина Евгения Олеговна - кандидат медицинских наук, доцент кафедры микробиологи, вирусологии и иммунологии ФГАОУ ВО Первый МГМУ им. И.М. Сеченова МЗ России (Сеченовский университет), Москва , Россия;

Чудилова Галина Анатольевна - кандидат биологических наук, доцент кафедры клинической иммунологи, аллергологии и лабораторной диагностики ФПК и ППС ФГБОУ ВО Кубанский государственный медицинский университет, Краснодар, Россия

Ковалева Светлана Валентиновна - кандидат медицинских наук, доцент кафедры клинической имуунологи, аллергологии и лабораторной диагностики ФПК и ППС ФГБОУ ВО Кубанский государственний медининский университет, Краснодар, Россия

Гарскова Наталья Викторовна- аспирант кафедры иммунопатологии и иммунодиагностики ФГБУ ФНКЦ ФМБА России

\section{Рецензенты:}

доктор медицинских наук, профессор Калюжин О.В.

доктор медицинских наук, профессор Балмасова И.П.

\section{АННОТАЦИЯ}

В учебно-методическом пособии дана характеристика врожденных и приобретенных интерферонопатий, приведена классификация интерферонопатий с учетом, как дефицита интерферонов различного типа, так и гиперпродукции интерферонов I типа, описаны особенности клинических проявлений различных видов интерферонопатий, рассмотрены дифференцированные подходы, как к таргетной терапии интерферонопатий I типа, ассоциированных с гиперпродукецией интерферона альфа, так и интерферонкорректирующей терапии.
у Учебно-методическое пособие «Врожденные и приобретенные интерферонопатии составлено на основании Федерального государственного образовательного стандарта высшего образова ия п̆ сцильсы кадров высшей Квалификации)» (МЗ РФ, 2014), написано на современном уровне, использованием результатов современным научных исследований по данной проблеме и може быть рекомендовано для студентов, клинических ординаторов и аспирантов медицинских вузов, слушателей факультетов непрерывного медицинского образования, врачей аллергологов-иммунологов, акушеров-гинекологов, педиатров, терапевтов, отоларингологов инфекционистов, врачей общей практики, врачей клинической лабораторной диагностики.

() Нестерова И.В., Халтурина Е.О., Чудилова Г.А., Ковалева С.В., Гарскова Н.В., 2020 r

○ АПО ФГБУ ФНКЦ ФМБА России, 2020г.

ISBN 978-5-6045471-0-6 
диагностики ФПК и ППС ФГБОУ ВО Кубанский государственный

медицинский университет, Краснодар, Россия

Гарскова Наталья Викторовна - аспирант кафедры иммунопатологии и иммунодиагностики ФГБУ ФНКЦ ФМБА России

\section{Рецензенты:}

доктор медицинских наук, профессор Калюжин О.В.

доктор медицинских наук, профессор Балмасова И.П.

Подписано в печать 07.11.2020 г.

$$
\text { Формат A5 }
$$

Бумага офсетная. Печать цифровая. Тираж 100 Экз. Заказ №205338-11-20

$$
\text { (Печатный салон МДМ) }
$$

г. Москва, ул.Дмитрия Ульянова д.20, к. 1 Тел. 8-495-256-10-00

\section{Содержание}

Список сокращений 4

Введение.

1. Врожденные и приобретенные интерферонопатии

2. Классификация интерферонопатий (Нестерова И.В., 2017) 19

3. Клинические и лабораторные аспекты диагностики интерферонопатий.

4. Основы дифференцированного подхода к интерферонкорректирующей терапии.

Вопросы для самоконтроля:

Литература 45

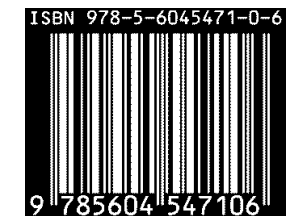




\section{Список сокращений}

ВтИД- вторичный иммунодефицит

НГ - нейтрофильные гранулоциты

ИЛ - интерлейкин

ИФН - интерферон

АГ - антиген

ЦМВ - цитомегаловирус

ВЭБ - вирус Эпштейна-Барр

ВЧГ 6 тип - вирус герпеса 6 тип

ВПГ1/2- вирус простого герпеса $1 / 2$ типа

\section{Учебно-методическое}

интерферонопатии» рекомендовано к изданию Ученым советом Академии постдипломного образования Федерального государственного бюджетного учреждения «Федеральный научно-клинический центр специализированных видов медицинской помощи и медицинских технологий Федерального медико-биологического агентства России», Москва, 2020 год.

\section{Авторы:}

Нестерова Ирина Вадимовна - доктор медицинских наук, профессор кафедры иммунопатологии и иммунодиагностики ФГБУ ФНКЦ ФМБА России (зав. кафедрой доктор медицинских наук, профессор Маркова Т.П.)

Халтурина Евгения Олеговна - кандидат медицинских наук, доцент кафедры микробиологи, вирусологии и иммунологии ФГАОУ ВО Первый МГМУ им. И.М. Сеченова МЗ России (Сеченовский университет), Москва, Россия;

Чудилова Галина Анатольевна - кандидат биологических наук, доцент кафедры клинической иммунологи, аллергологии и лабораторной диагностики ФПК и ППС ФГБОУ ВО Кубанский государственный медицинский университет, Краснодар, Россия

Ковалева Светлана Валентиновна - кандидат медицинских наук, доцен' кафедры клинической иммунологи, аллергологии и лабораторной 
16. Сепиашвили Р.И. Физиология иммунной системы.-М.: Медицина-Здоровье, 2019.-360 с.: ил.41, табл.13 ISBN 594255-044-4

17. Nesterova I., Kovaleva S., Chudiliva G., Lomtatidze L. Defects in functioning of interferon and immune systems and their correction in chronic active Epstein-Barr infection. // Allergy, Asthma \& Immunophysiolosy: from basic science to clinical application. - Medimond International Proceedings. 2012. P. $187-191$.

18. Нестерова И.В., Ковалева С.В.,. Клещенко Е.И, Чудилова Г.А., Ломтатидзе Л.В., Шинкарева О.Н., Парфенов В.В., Кольцов В.Д. Оптимизация тактики интерфероно- и иммунотерапии в реабилитации иммунокомпрометированных детей с повторными респираторными и герпетическими вирусными инфекциями. // Педиатрия. - 2014.- Т.93. №3. С.66-72.

19. Нестерова И.В. Интерфероны в практике клинициста: лучшие друзья или опасные враги. // Аллергология и иммунология. 2016. Том17. №3. С.189-Реферат

\section{Введение}

Данное учебно-методическое пособие содержит новейшие научные данные суммирующие представления о нарушениях системы интерферона интерферонопатиях.

Необходимость написания такого пособия связана с тем, что бурное развитие методов лабораторной и клинической диагностики выявило целый пласт состояний и заболеваний, ассоциированных с нарушениями в системе интерферона, в связи с чем возникла необходимость систематизировать накопленные данные, изучить механизмы возникающих нарушений и дефектов в системе ИФН, разработать комплексные подходы к диагностике этих патологических состояний, создать программы таргетной иммунотропной терапии.

Авторы описывают клинические особенности интерферонопатии I типа, связанной с избыточной экспрессией ИФН $\alpha$ - редкого генетического заболевания болезни Менделя. Некоторые аутоиммунные заболевания 
(СКВ, васкулит и др.), синдром иммунной дисрегуляции также характеризуется гиперсекрецией ИФН описаны наиболее распространенные интерферонопатии дефицит ИФН: врожденный или приобретенный дефицит ИФН $\alpha / \beta$ и ИФН $\gamma$ у детей и взрослых. Дефицит ИФН $\alpha / \beta$ ассоциирован с тяжелыми рецидивирующими вирусными инфекциями, а дефицит ИФНү вызывает микобактериальную инфекцию. Описаны методы интерферон-корригирующей терапии.

Цель терапии интерферонопатий I типа - связывание ИФН $\alpha$ моноклональными антителам и нормализация его уровня в сыворотке крови, тканях и других биологических жидкостях. С другой стороны, пациенты с врожденным дефицитом ИФН $\alpha$ нуждаются в заместительной ИФНтерапии. При приобретенном дефиците ИФНа проводится дифференцированная интерферон-корригирующая терапия. Как в заместительной, так и в интерферон-корригирующей терапии могут быть использованы рекомбинантные человеческие ИФН $\alpha$ 2b в комплексе с антиоксидантами. from the International Union of Immunological Societies Expert Committee for Primary Immunodeficiency. // Frontiers in Immunology. 2014|. Vol.5. \#6. P.1-33.

12. Andersen L., Mørk N., Reinert L., et al. Functional IRF3 deficiency in a patient with herpes simplex encephalitis. // JEM. 2015. Vol.212. \#9. P.1371-1379.

13. Нестерова И.В.,Сепиашвили Р.И. Иммунологические препараты и современная иммунотерапия в клинической иммунологии и медицине // Аллергология и иммунология. 2000. №3.C. 18-28.

14. Нестерова И.В. Иммуномодулирующая терапия направленного действия: сегодняшняя реальность и перспективы // Аллергология и иммунология. 2015. №1. С. 18-20.

15. Сепиашвили Р.И. Основные принципы применения иммуномодулирующих препаратов в клинической практике // Аллергология и иммунология. 2015. Том15. №1 C.70-74, 
7. Khamashta M, Merrill J.,Werth V. et al. Sifalimumab, an antiinterferon- $\alpha$ monoclonal antibody, in moderate to severe systemic lupus erythematosus: a randomised, double-blind, placebo-controlled study. // Ann Rheum Dis. 2016. Vol.75. \#11. P.1909-1916.

8. Kalunian K., Merrill J., Maciuca R. et al. A Phase II study of the efficacy and safety of rontalizumab (rhuMAb interferon- $\alpha$ ) in patients with systemic lupus erythematosus (ROSE). // Ann Rheum Dis. 2016. Vol.75. \#1. P.196-202.

9. Furie R., Khamashta M., Merrill J. et al. Anifrolumab, an Anti-Interferon- $\alpha$ Receptor Monoclonal Antibody, in Moderate-to-Severe Systemic Lupus Erythematosus. // Arthritis Rheumatol. 2017.vol.69. \#2. P. 376-386.

10. Нестерова И.В., Малиновская В.В., Тараканов.В.А., Ковалева С.В. Интерфероно- и иммунотерапия в практике лечения часто и длительно болеющих детей и взрослых. Capricorn Publishing, Inc.USA, UK, Russia. 2004. 158c.

11. Al-Herz W., Bousfiha A., Casanova J.-L.et al. Primary immunodeficiency diseases: an update on the classification

\section{1. Врожденные и приобретенные интерферонопатии}

«Интерферонопатии» - в течение последних 5 лет этот термин активно эксплуатируется в зарубежной научной литературе. Ряд авторов подразумевает под этим термином только врожденные генетические расстройства системы интерферонов (ИФН) -интерферонопатии I типа, сопровождающиеся гиперпродукцией ИФН $\alpha$, которые ассоциированы с определенной клинической симптоматикой.

Термин интерферонопатия - сложное слово, имеющее в своём составе два корня: интерферон и патия. В тоже время корень патия, что означает страдание (от греческого pathos - болезнь), - часть сложных слов, означающий патологию какого-либо органа или системы без конкретного уточнения. Например, общее название болезней головного мозга энцефалопатия, общее название болезней почек нефропатия, общее название болезней желудка - гастропатия и т.д. Отсюда и термин интерферонопатия означает общую патологию системы ИФН, врожденную или приобретенную, которая включает следующие типы расстройств системы 
ИФН: дефицит, состояние неадекватной отвечаемости при контакте с вирусами, бактериями, мутировавшими или опухолевыми клетками - парализис системы ИФН, гиперпродукцию ИФН.

Интерфероны играют центральную роль в иммунной защите против вирусной и бактериальной инфекции.

\section{Семейство интерферонов}

Интерферон (ИФН) был открыт в 1957 г. А. Айзексом и Ж. Линдеманом при изучении интерференции вирусов (от лат. inter - между, ferens - несущий). Интерференция это явление, когда ткани, инфицированные одним вирусом, становятся устойчивыми к заражению другим вирусом. Было установлено, что такая резистентность связана с продукцией зараженными клетками особого белка, который и был назван интерфероном.

Интерфероны - цитокины, проявляющие противовирусное, антипролиферативное и иммуномодулирующее действие

В настоящее время интерфероны хорошо изучены. Они представляют собой семейство гликопротеидов с

\section{Литература}

1. Crow Y. Type I interferonopathies: a novel set of inborn errors of immunity. //Ann N Y Acad Sci. 2011. Nov;1238 P.91-98;

2. Günther C., Schmidt F., König N., Lee-Kirsch M. Type I interferonopathies. Systemic inflammatory diseases triggered by type I interferons. // Z Rheumatol. 2016. Vol.75. \#2. P.134140 ;

3. Lee-Kirsch M. The Type I Interferonopathies. //Annu Rev Med. 2017.vol. 68. \#14. P.297-315.

4. Crow Y. Human type I interferonopathies. // Cytokine. 2015. vol.76. \#1. P. 58.

5. Rodero M., Crow Y. Type I interferon-mediated monogenic autoinflammation: The type I interferonopathies, a conceptual overview.// J Exp Med. 2016. Vol. 213. \#12. P.2527-2538.

6. Caielli S., Athale S., Domic B., et al. Oxidized mitochondrial nucleoids released by neutrophils drive type I interferon production in human lupus. // J Exp Med. 2016. Vol.213. \#5. P. 697-713. 
гранулоцитов, нарушения их фагоцитарной и микробицидной активности.

9. Индуцированную продукцию ИФН

10. Вторичные дефекты в системе ИФН, характеризующиеся нарушениями индуцированной продукции ИФН $\alpha$ и ИФН $\gamma$ часто манифестируют повторными эпизодами ОРВИ от 8-10 до 24 и более раз в год и различными хроническими герпесвирусными инфекциями.

11. Клиническими проявлениями инфекционного синдрома

12. Симптомокомплекс, который манифестирует жалобами на выраженную слабость, повышенную утомляемость, снижение работоспособности, нарушения памяти, инсомию, нарушения засыпания, подавленное настроение (гипотимия) и пр

13. В 1957 г. А. Айзексом и Ж. Линдеманом при изучении интерференции вирусов

14. В использовании дифференцированных подходов, предполагающих применение максимально высоких доз препарата с самого начала лечения, с переходом на средние, а затем на малые дозы препарата каждые 2-3 4 недели, вплоть до полной отмены.

15. Потому что индукторы интерфероногенеза оказывают излишнее дополнительное индуцирующее воздействие на уже истощенную систему ИФН. молекулярной массой от 15000 до 70 000. В зависимости от источника получения эти белки делят на интерфероны I, II и III типов.

I тип включает ИФН $\alpha$ и $\beta$, которые продуцируются инфицированным вирусом клетками: ИФН- $\alpha$ лейкоцитами, ИФН- $\beta$ - фибробластами. В последние годы описаны три новых интерферона: ИФН- $/ \varepsilon$ (трофобластный ИФН), ИФН- $\lambda$ и ИФН-К. В противовирусной защите участвуют ИФН $-\alpha$ и $\beta$.

Механизм действия ИФН- $\alpha$ и ИНФ- $\beta$ связан не только с прямым влиянием на вирусы. Он обусловлен активацией в клетке ряда генов, блокирующих репродукцию вируса. Ключевое звено - индукция синтеза протеинкиназы R, которая нарушает трансляцию вирусной мРНК и запускает апоптоз зараженных клеток через Bc1-2 и каспаза-зависимые реакции. Другой механизм - это активация латентной РНКэндонуклеазы, которая вызывает деструкцию вирусной нуклеиновой кислоты. Третий механизм- ингибирование синтеза вирусных белков за счет образования под действием 
фосфорилированию и инактивации фактора элонгации-2.

Секретированные ИФН связываются с расположенными на мембране клеток соответствующими рецепторами

IИФНаR, что ведет к активации киназ Tyk2 and Jak1, которые подвергаются фосфорилированию и активируют белки сигнальной трансдукции и активации транскрипции 1 (STAT1) and STAT2. В результате формируется гетеротримерный комплекс, известный как ИФНстимулирующий генный фактор-3 (ISGF3), в состав которого входит ИФН регулирующий фактор 9 (IRF9). Активация Jak негативно регулируется ИФН-индуцибельными белками SOCS1 и SOCS3. Связывание ISGF3 промотирует ISGs, что ведет к их транскрипционной активации и коллективным действиям сотен ISGs, в результате продуцируется большое количество индуцированного ИФН, который ингибирует как вирусную репликацию, так и распространение вирусов. Каждый этап экспрессии ISGs, может быть поврежден различными вирусами.
15. Почему использование индукторов интерфероногенеза не показано у пациентов с интерфенанопатиями?

\section{Ответы на вопросы самоконтроля}

1. Три

2. Механизм действия ИФН- $\alpha$ и ИНФ- $\beta$ связан не только с прямым влиянием на вирусы. Он обусловлен активацией в клетке ряда генов, блокирующих репродукцию вируса.

3. Термин интерферонопатия означает общую патологию системы ИФН, врожденную или приобретенную, которая включает следующие типы расстройств системы ИФН: дефицит, состояние неадекватной отвечаемости при контакте с вирусами, бактериями, мутировавшими или опухолевыми клетками парализис системы ИФН, гиперпродукцию ИФН.

4. Врожденные и приобретенные интерферонопатии

5. Генетические и молекулярные нарушения, имеющие место при редких болезнях Менделя

6. Да, могут.

7. Ингибирование синтеза и продукции ИФН $\alpha / \beta$; антигенная мимикрия

8. Программа включает коррекцию нарушений индуцированной продукции ИФН $\alpha$ и ИФН $\gamma$, а также устранение дисфункции нейтрофильных 


\section{Вопросы для самоконтроля:}

1. Сколько видов интерферонов известно в настоящее время?

2. Каковы основные механизмы действия ИНФ?

3. Что подразумевает термин « интерферонопатия»?

4. Какие виды интерферонопатий выделяют в настоящее время?

5. При каком генетическом расстройстве наблюдается неадекватно высокая гиперпродукция ИФН I типа?

6. Могут ли вирусы оказывать подавляющее влияние на систему ИНФ?

7. Каковы механизмы ускользания вирусов от противовирусной защиты организма?

8. Что включает в себя программа интерферонотерапии?

9. Какой вид продукции ИНФа удается восстановить наиболее полноценно в программе интерферонотерапии?

10. Чем характеризуются вторичные дефекты в системе ИНФ?

11. Как чаще всего манифестируют клинически дефекты в системе ИНФ?

12. Как клинически проявляется поствирусный синдром хронической усталости?

13. Когда и кем впервые были открыты интерфероны?

14. В чем состоит суть ступенчатой ИФН-терапии?
II тип включает ИНФ- $\gamma$. Он продуцируется Т-лимфоцитами и ЕК после антигенной стимуляции. Для этого типа ИНФ характерно преобладание иммуномодулирующих эффектов, он реализуют свое действие на клетки через рецепторы II типа.

III тип включает ИФН $\lambda$ : ИЛ-28А ИЛ-28В ИЛ-29. Этот тип ИНФ принадлежит к семейству интерлейкина-10 и его действие на клетки реализуется одновременно через рецепторы I типа и рецепторы для ИЛ-10.

Интерферон синтезируется клетками постоянно (базальная секреция или спонтанный уровень), его концентрация в крови в норме мало меняется. Однако продукция ИНФ усиливается при инфицированию клеток вирусами или действии его индукторов - интерфероногенов (вирусной РНК, ДНК, сложных полимеров и др).

Для синтеза интерферонов в организме необходима активация клеток. Тoll-подобные рецепторы (TLR); RIGподобные рецепторы (RLR) - RIG-1; MDA5, а также cGas 
(циклическая GMP-AMP-синтаза) участвуют в распознавании чужеродных сайтов и сайтов нуклеиновых кислот хозяина. Основными индукторами синтеза интерферонов I типа являются двухцепочечная и одноцепочечная РНК вирусов, а также бактериальная ДНК. RIG-подобные рецепторы распознают как одноцепочечные, так и двухцепочечные вирусные РНК, тогда как cGAS (циклическая GMP-AMPсинтаза), напротив, распознает двухцепочечные ДНК и РНК: ДНК-дуплексы, образующиеся во время репликации ретровирусов, и катализируют синтез сGMP-AMP, который является основным агонистом белка-адаптера - STING. После связывания PHK RIG-1 и MDA5 связывают белок-адаптер MAVS. И STING, и MAVS стимулируют нижестоящие сигнальные каскады, которые активируют многочисленные киназы и, в конечном итоге, приводят к фосфорилированию IRF3 и индукции синтеза интерферона. Синтезированный ИФН типа I связывается с соответствующими рецепторами ИФН $\alpha$, расположенными на клеточной мембране, что приводит к активации киназы Tyk2 и Jak1, которые
В тоже время локальное и системное применение рекомбинантного ИФН $22 \mathrm{~b}$ в комбинации с антиоксидантами - Виферона при врожденных и приобретенных дефектах в системе ИФН, ассоциированных с вирусным инфекционным синдромом, - при индивидуальном подборе дифференцированной дозы, с учетом глубины дефицита и адекватного по длительности - пролонгированного курса,является оптимальным, поскольку сопровождается позитивными клинико-иммунологическими эффектами при отсутствии каких-либо негативных и побочных эффектов.

Наш более чем 20-тилетний опыт свидетельствует о том, что применение Виферона у лиц с врожденными или приобретенными дефектами в системе ИФН, без генетической предрасположенности к манифестации аутоиммунных процессов, демонстрирует позитивный клинический эффект и не представляет опасности. 
Группа 1 получала терапию препаратом Вифероном с постепенным снижением дозы. Группа 2 дополнительно к терапии препаратом Виферон получала иммунотерапию glucosaminylmuramyldipeptide (препарат Ликопид). Получен позитивный клинико- иммунологический эффект, более выраженный в группе 2, получавшей комбинированную интерфероно- и иммунотерапию (Рисунок 4).

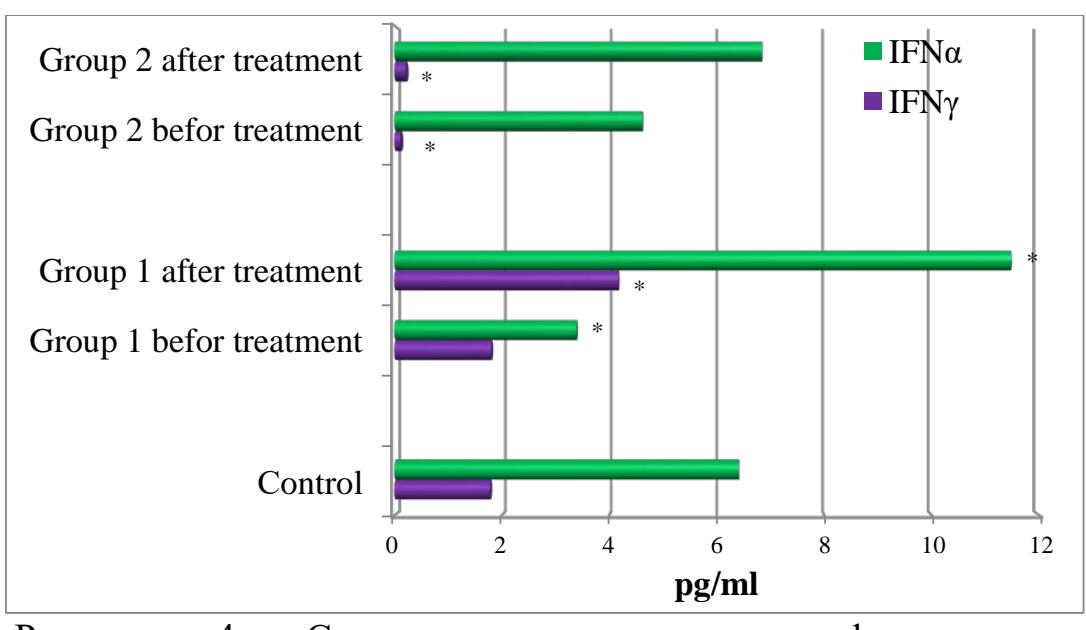

Рисунок 4. Состояние системы интерферонов у иммунокомпрометированных детей с возвратными респираторными вирусными инфекциями на фоне различных программ интерероно- и иммунотерапии. Группа 1 получала терапию препаратом Вифероном с постепенным снижением дозы. Группа 2 дополнительно к терапии препаратом Виферон получала иммунотерапию глюкозаминилмурамилдипептид (*- $<<0,05$, относительно уровня контроля). подвергаются фосфорилированию и активируют белки сигнальной трансдукции и активации транскрипции (STAT1 и STAT2). В результате образуется гетеротримерный комплекс, известный как IFN-стимулирующий фактор гена-3 (ISGF3), который включает регуляторный фактор IFN 9 (IRF9). Активация Jak негативно регулируется индуцируемыми ИФН $\alpha$ белками SOCS1 и SOCS3. Связывание ISGF3 стимулирует ISG, что приводит к их активации транскрипции и коллективным действиям сотен ISG, что приводит к образованию большого количества индуцированного ИФН, который ингибирует как репликацию вируса, так и распространение вирусов. Быстрая секреция ИФН I типа, а затем быстрый синтез индуцируют активность клеток врожденного и адаптивного иммунитета путем активации провоспалительных цитокинов, которые активируют клеточный и гуморальный противовирусный иммунный ответ (рис. 1). 


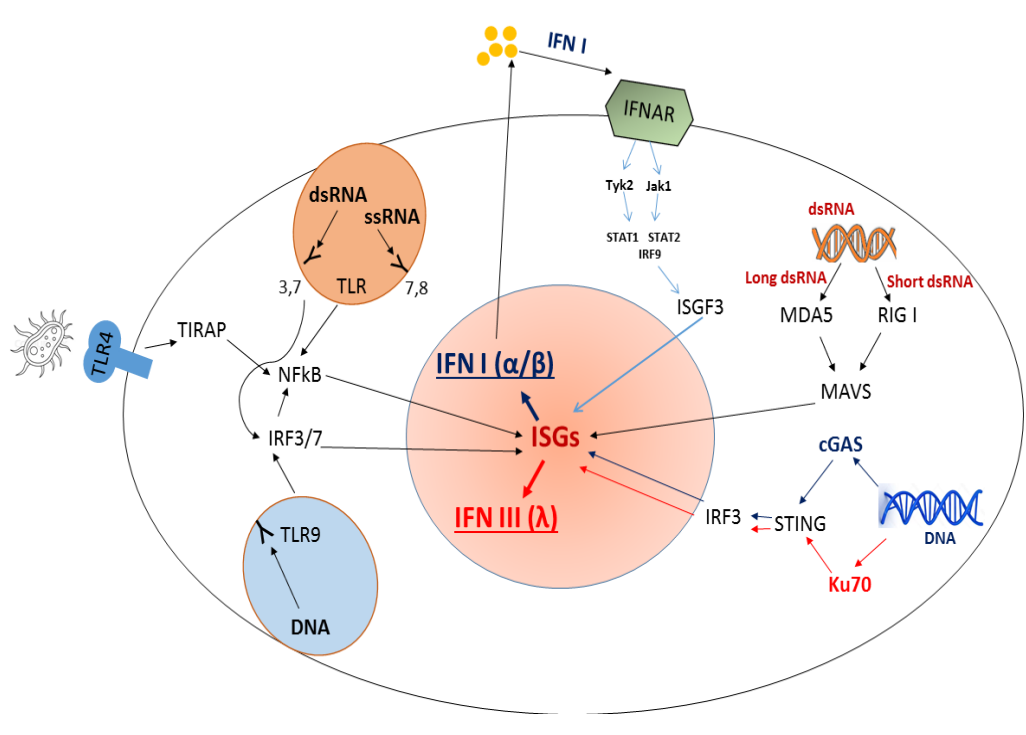

Рисунок 1. Молекулярные механизмы индукции синтеза интерферона I, III типа. PAMPs: dsPHК - двухцепочечная РНК, sSРНК - одноцепочечная РНК; Сенсоры нуклеиновых кислот: cGAS - циклическая GMP-AMP-синтаза, MDA5 протеин 5, связанный с дифференцировкой меланомы, RIG-I - RIG-I подобный рецептор dsPHК фермента геликаза; Белкиадаптеры: TIRAP - домен рецептора толл-интерлейкина 1 (TIR), содержащий адаптер-белок, MAVS митохондриальный противовирусный сигнальный белок, STAT - активатор трансдукции и транскрипции; Ядерные факторы: IRF - ИФН-регуляторный фактор, NF-kB - ядерный фактор каппа-легкой цепи-энхансер активированных Вклеток; IFN $\alpha \mathrm{R}$ - рецептор ИФНа; ISGs - интерферонстимулированные гены; Tyk - тирозинкиназа; Jak - Янус киназа.

$$
\text { При острой вирусной инфекции значительно }
$$

повышаются уровни ИФН и более $70 \%$ клеток находятся в продемонстрировало возможность восстановления системы ИФН, в первую очередь за счет восстановления индуцированной продукции ИФН $\alpha$. Позитивный клинический эффект состоял в значительном сокращении количества ОРВИ в год в 3-4.5 раза по сравнению с частотой ОРВИ до применения моно-интерферонотерапии.

В тоже время для пациентов со вторичными комбинированными нарушениями в системе ИФН и иммунной системе, ассоциированными с повторными ОРВИ от13 до 24 и более в год и хроническими герпес-вирусными ко-инфекциями, нами была разработана программа комбинированной интерфероно- и иммунотерапии. Программа учитывала не только нарушения индуцированной продукции ИФН $\alpha$ и ИФН $\gamma$, но и дисфункции нейтрофильных гранулоцитов, нарушения их фагоцитарной и микробицидной активности. Ее целью было не только восстановление системы ИФН, но и реставрация системы нейтрофильных гранулоцитов и других звеньев противовирусной защиты. 
мы полагаем нецелесообразным: во первых - из-за наличия побочных эффектов, в т.ч. развития психогенной депрессии и синдрома хронической усталости, во вторых - из-за опасности излишнего дополнительного индуцирующего воздействия на уже истощенную систему ИФН. С другой стороны нашими исследованиями показана позитивная, но краткосрочная эффективность коротких курсов интерферонотерапии у детей из группы ЧДБ, когда короткие курсы препарата Виферон способствовали регрессии клинических проявлений ОРВИ, но не профилактировали возникновения новых эпизодов ОРВИ. Разработанная нами программа локальной (гель, мазь) и системной (суппозитории) монотерапии препаратом Виферон рекомбинантный ИФН $\alpha 2 b$ в комбинации с антиоксидантами (витамин Е и витамин С) с использованием дифференцированных подходов, предполагает применение максимально высоких доз препарата с самого начала лечения, с переходом на средние, а затем на малые дозы препарата каждые 2-3 -4 недели, вплоть до полной отмены. Применение состоянии антивирусного статуса, т.е. защищены от внедрения вирусов, и способны активно их обезвреживать. В течение последних15 лет описаны врожденные генетические дефекты синтеза ИФН $\alpha / \beta$ и ИФН $\gamma$, дефекты рецепторов к ИФН и ИФН $\gamma(\mathrm{IFN} \alpha \mathrm{R}$ и IFN $\gamma \mathrm{R})$, которые сопровождаются клиническими проявлениями тяжелой вирусной и/или микобактериальной инфекции. Многочисленными исследованиями убедительно показано существование вторичных, приобретенных нарушений в системе ИФН, которые влекут за собой снижение противовирусной резистентности. Так, вирусы используют различные контрмеры для борьбы с системой ИФН и способны повреждать синтез и продукцию ИФН на разных этапах интерфероногенеза, а тяжелые вирусные инфекции приводят к её истощению и, как следствие, присоединению вторичной инфекции. При этом вирусы могут не только ускользать от воздействия ИФН, но и ингибировать действие уже синтезированных ИФН. Эти вторичные дефекты ИФН типа I приводят к возникновению тяжелых вирусных инфекций 
(герпесвирусный энцефалит), рецидивирующих острых респираторных вирусных инфекций, хронической рецидивирующей инфекции ВПГ I, атипичных хронических инфекций ВЭБ и других атипичных случаев вирусной инфекции. Было показано, что вирусы могут избегать воздействия ИФН, ингибировать действие и синтез ИФН с помощью различных молекулярных механизмов. Многочисленные исследования показали, что многие вирусы (все герпесвирусы, большинство респираторных вирусов, вирусы гепатита В и С и т. Д.) Продуцируют белки, способные ингибировать синтез и продукцию ИФН $\alpha$ / и ИФНү. Вирусы могут повредить каждую стадию экспрессии ISG .

Описаны приобретенные дефекты в системе ИФН у лиц, страдающих возвратными ОРВИ и различными хроническими герпес-вирусными инфекциями. В последние годы в научной литературе появилось описание клинических особенностей интерферонопатий I типа, ассоциированных с гиперпродукцией ИФН $\alpha$, которые встречаются при редких
Вторичные дефекты в системе ИФН, характеризующиеся нарушениями индуцированной продукции ИФН повторными эпизодами ОРВИ от 8-10 до 24 и более раз в год и различными хроническими герпес-вирусными инфекциями. Иммунокомпрометированные дети и взрослые, страдающие повторными ОРВИ, почти в 100\% случаев имели различные хронические герпес-вирусные инфекции. При этом хронический ороназофациальный герпес и/или генитальный герпес рецидивировали с высокой степенью частоты от 10 до 24 и более раз в год, а атипичная хроническая активная ВЭБ инфекция с проявлениями поствирусного синдрома хронической усталости имела место более, чем у 50\% пациентов. Не вызывает сомнения существование актуальной необходимости разработки новых подходов к лечению таких пациентов, которые в $100 \%$ случаев имеют нарушение индуцированной продукции ИФН $\alpha$ и в более чем $50 \%$ случаев - ИФНү. Применение у этой группы пациентов парентеральных интерферонов и индукторов интерферонов, 
высокими, средними и низкими дозами, которая при комбинированных иммунодефицитах может сочетаться с иммуномодулирующей терапией, направленной на восстановления дефектных звеньев противовирусного иммунитета. При этом необходимо учитывать и различную степень выраженности вирусного инфекционного синдрома, и глубину дефицита ИФНа, а также особенности нарушений иммунной системы при втИД.

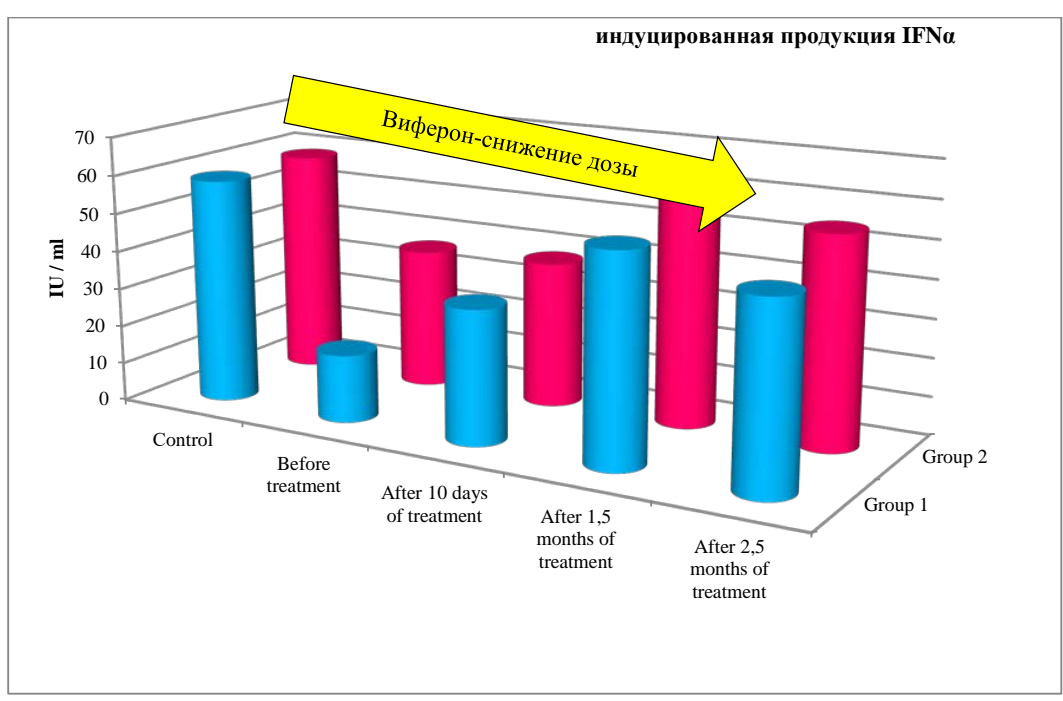

Рисунок 3. Восстановление индуцированной продукции ИФН $\alpha$ на фоне использования дифференцированных доз препарата Виферон с постепенным снижением дозы, вплоть до полной отмены через 2.5 месяца от начала интерферонотерапии. генетических болезнях Менделя, некоторых аутоиммунных заболеваниях, синдроме иммунной дисрегуляции.

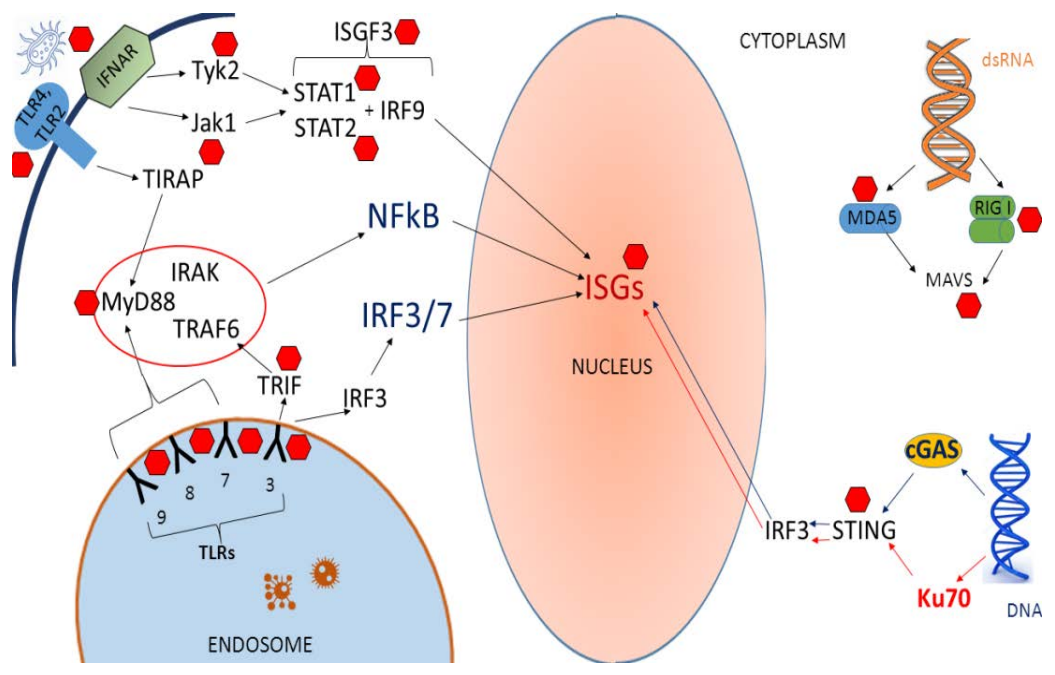

Рисунок 2. Блокировка вирусами сигнальных путей для индукции интерферона (красные шестиугольники указывают точки приложения всех герпесвирусов, большинства респираторных вирусов, вирусов гепатита В и С и т. д.). дцРНК - двухцепочечная РНК; IRF - ИФН-регуляторный

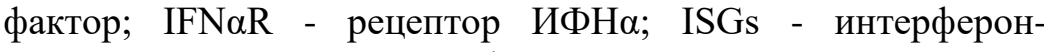
стимулированные гены; Tyk - тирозинкиназа; Jak - Янус киназа; NF-kB - ядерный фактор каппа-легкой цепи активированных В-клеток; cGAS - циклическая GMP-AMP синтаза; MAVS - митохондриальный противовирусный сигнальный белок; MDA5 - белок, ассоциированный с дифференциацией меланомы 5 ; STAT - активатор трансдукции и транскрипции; TRIF - домен, содержащий TIR-адаптер, индуцирующий ИФН- $\beta$; Кu70 - компонент негомологичного пути присоединения, который восстанавливает двухцепочечные разрывы ДНК. 
Таким образом, патология системы интерферонов весьма многообразна, однако, информация, представленная отечественными и зарубежными авторами, не очень хорошо систематизирована. Все известные на сегодняшний день нарушения системы ИФН, врожденного или приобретенного происхождения, включающие различные виды расстройств: дефицит, состояние неадекватной отвечаемости при контакте с вирусами, бактериями, мутировавшими или опухолевыми клетками - парализис системы ИФН, гиперпродукция ИФН это патология системы ИФН, - интерферонопатии. Базируясь на собственном опыте, опыте отечественных и зарубежных исследователей, нами разработана классификация интерферонопатий, которая приводится ниже. (Нестерова И.В. Врожденные и приобретенные интерферонопатии: дифференцированные подходы K интерферонкорректирующей терапии, 2017). врожденные или приобретенные нарушения в системе ИФН. В случаях наличия первичных нарушений в системе ИФН пациенты нуждаются в проведении базисного курса восстановительной терапии, дающего возможность максимально элиминировать вирусные антигены, а далее необходимо осуществить подбор доз для проведения постоянной заместительной терапии Вифероном.

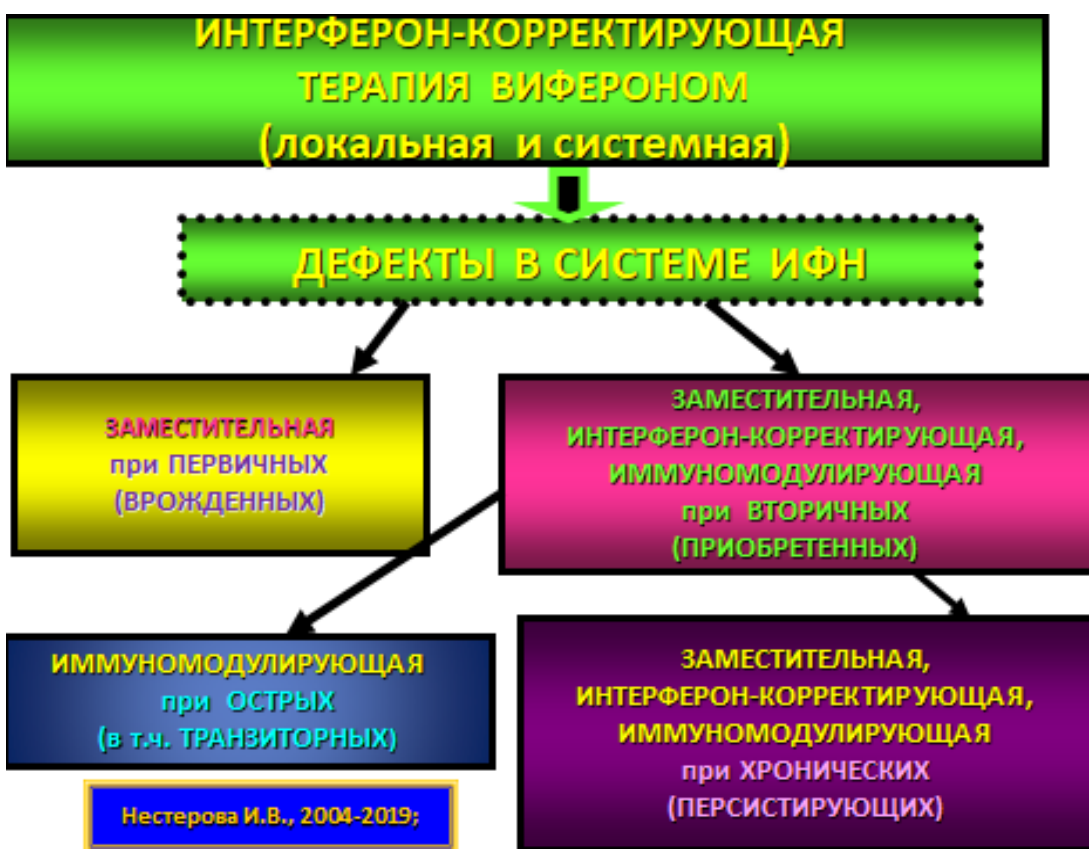

B случаях приобретенного интерферонодефицита, проводится дифференцированная терапия Вифероном 
инфекция с проявлениями поствирусного синдрома хронической усталости имела место более, чем у 50\% пациентов. Не вызывает сомнения существование актуальной необходимости разработки новых подходов к лечению таких пациентов, которые в $100 \%$ случаев имеют нарушение индуцированной продукции ИФН $\alpha$ и в более чем $50 \%$ случаев - ИФН $\gamma$.

\section{4. Основы дифференцированного подхода к интерферон-}

корректирующей терапии

В течение более чем 20 лет нами разрабатываются программы интерферонотерапии отечественным препаратом ИФН - рекомбинантный человеческий ИФНа2b в комбинации с антиоксидантами - Виферон. В течение этого периода доказана безопасность, противовирусная и иммуномодулирующая эффективность Виферона, отсутствие побочных эффектов, присущих препаратам парентеральных ИФН, отсутствие образования антител против ИФНа2b. Заместительная терапия Вифероном показана лицам, имеющим первичные, генетически обусловленные,
2. Классификация интерферонопатий (Нестерова И.В., 2017)

\section{I. Врожденные интерферонопатии}

\section{1. Дефицит интерферонов}

1.1. дефицит интерферона альфа (ИФНК);

1.2. дефицит интерферона бета (ИФНß);

1.3. дефицит интерферона гамма (ИФН $\gamma)$;

\section{2. Гиперпродукция интерферонов}

\section{1. Гиперпродукция ИФНа:}

2.1.1. Аутовоспалительные синдромы и аутоиммунные заболевания (системная красная волчанка, системные васкулиты, дерматомиозит, синдром Дауна);

2.1.2 Интерферонопатии I типа: Aicardi-Goutières syndrome, familial chilblain lupus, spondyenchondromatosis, proteasome-associated auto-inflammatory syndrome (PRAAS), Singleton-Merten syndrome (интерферонопатии Менделя).

II. Приобретенные - вторичные интерферонопатии

1.1. Дефицит интерферонов:

1.1.1. дефицит интерферона альфа (ИФНо); 


\subsection{2. дефицит интерферона бета (ИФНß);}

\subsection{3. дефицит интерферона гамма (ИФН $\gamma)$;}

\section{1 Парализис системы интерферонов:}

\subsection{1. блокада адекватного ответа интерферона альфа}

\section{(ИФН $)$;}

\subsection{2. блокада адекватного ответа интерферона бета}

\section{(ИФН}

\subsection{3. блокада адекватного ответа интерферона гамма}

(ИФН $\gamma)$

\section{3. Гиперпродукция интерферонов:}

\section{1. Цитокиновый шторм.}

ИФН играют центральную роль в иммунной защите против вирусной инфекции. Активация ИФН I типа индуцируется паттерн-распознающими рецепторами врожденной иммунной системы, которые распознают патоген-ассоциированные нуклеиновые кислоты (РНК, ДНК). Быстрая секреция, а в дальнейшем и быстрый синтез ИФН I типа индуцирует активность клеток врожденного и адаптивного иммунитета посредством запуска секреции
ИФН статуса применяется как в научных исследованиях, так и в практике лабораторной диагностики для определения нарушений интерфероногенеза при различных воспалительных процессах.

Установлено, что характер изменений основных показателей ИФН статуса напрямую связан с клиническими формами заболеваний, а также с особенностями медикаментозного лечения.

Вторичные дефекты в системе ИФН, характеризующиеся нарушениями индуцированной продукции ИФН $\alpha$ и ИФН $\gamma$ часто манифестируют повторными эпизодами ОРВИ от 8-10 до 24 и более раз в год и различными хроническими герпес-вирусными инфекциями. Иммунокомпрометированные дети и взрослые, страдающие повторными ОРВИ, почти в 100\% случаев имели различные хронические герпес-вирусные инфекции. При этом хронический ороназофациальный герпес и/или генитальный герпес рецидивировали с высокой степенью частоты от 10 до 24 и более раз в год, а атипичная хроническая активная ВЭБ 
его титра, при котором задерживается деструкция монослоя клеток от внесенного тест-вируса VSV, т.е. то максимальное разведение, при котором наблюдается 50-процентная защита клеток монослоя от ЦПД VSV.

Существуют две группы методов определения ИФН: иммунохимический (иммуноферментный и радиоиммунный анализ) и метод, основанный на определении биологической активности ИФН. Иммунохимические методы не позволяют анализировать биологическую активность ИФН и при исследовании клинического материала могут давать ложно-положительные результаты.

Метод, позволяющий тестировать биологическую активность ИФН, основан на определении противовирусного действия ИФН в биологической тестсистеме, представляющей собой культуру клеток и тествирус с его цитопатическим действием.

Определение ИФН статуса используется как интегральный показатель функционального состояния системы ИФН и эффективности проводимого лечения. В России определение провоспалительных цитокинов и, таким образом, происходит активация клеточного и гуморального звеньев противовирусного иммунного ответа. ИФН I типа синтезируются эпителиальными клетками, многими клетками иммунной системы, в том числе плазмацитоидными дендритными клетками, распознающими чужие или собственные нуклеиновые кислоты. Генетические и молекулярные нарушения, имеющие место при редких болезнях Менделя, ассоциированы с гиперпродукцией ИФН I типа, возникающей вследствие врожденных нарушений внутриклеточного нуклеинового метаболизма, дефицита ДНК-азы или дефектов сенсорного распознавания нуклеиновых кислот. В результате этих расстройств в цитоплазме клеток происходит образование большого количества собственных нуклеиновых кислот. В ответ возникает активное распознавание ДНК и патологическая гиперпродукция ИФН I типа, которые запускают гиперактивацию аутоиммунитета, что приводит к развитию аутоиммунного воспаления, поражающего центральную и 
периферическую нервную систему, вызывающего поражения кожи и сосудов (васкулиты), костей и суставных поверхностей, легких и т.д. Таким образом, быстрая эффективная реакция иммунитета на чужеродные нуклеиновые кислоты позитивна, когда приводит к активации ИФН I типа во время вторжения патогенов и реализации противомикробной защиты, но крайне негативна, когда она происходит в ответ на гиперпродукцию собственной ДНК, возникающую в результате нарушений метаболизма собственных нуклеиновых кислот. Полученные данные о врожденных нарушениях внутриклеточного метаболизма нуклеиновых кислот и связанных с этим генетических и молекулярных дефектах, существенно расширяют понимание механизмов, которые защищают организм от ненадлежащей иммунной активации, что в результате может позволить разработать новые терапевтические подходы к лечению аутовоспалительных расстройств и некоторых аутоиммунных заболеваний. Генетические расстройства - болезни Менделя (Aicardi- локализации, папилломавирусной инфекции кожи и слизистых, характеризующихся упорно-рецидивирующим течением, когда частота повторных ОРВИ и/или обострений герпетической инфекции (ВПГ1, ВПГ2) может составлять от 14 до 24 раз в год и более.

\section{3. Клинические и лабораторные аспекты диагностики}

\section{интерферонопатий}

Исторически исследование многофункциональных белков ИФН началось с 50-х годов прошлого столетия, с открытия ИФН Isaacs А. И Lindenmann J. в 1957 году.

В понятие "ИФН статус" входит определение биологической функциональной активности ИФН I $(\alpha / \beta)$ и II $(\gamma)$ типов, синтезированных лейкоцитами периферической крови при их стимуляции и уровень биологически активного ИФН в сыворотке крови (спонтанная и индуцированная продукция)

\section{За единицу биологической (функциональной) активности}

ИФН (ед/мл) принимается величина обратного разведения 
случаев сопряжено с наличием у них моно- или микстгерпес-вирусной инфекции. У таких пациентов в ряде случаев частота рецидивов хронической герпетической (HSV1/2) инфекции фациальной, и/или генитальной локализации, может достигать 16-24 эпизодов в год, а такая герпес-вирусная инфекция, как вирус Эпштейна-Барр может вызывать возникновение атипичной хронической активной ВЭБ инфекции с сопутствующим синдромом хронической усталости. Безусловно, что для таких пациентов чрезвычайно актуальным остается вопрос разработки новых подходов к проведению терапии препаратами ИФН при врожденных и приобретенных дефектах в системе ИФН. Очевидно, что для этих целей весьма сложным является применение парентеральных ИФН, в связи с наличием многочисленных побочных эффектов. Следует учитывать также неэффективность использования коротких курсов терапии ИФН для восстановления нормального функционирования системы ИФН при рекуррентных ОРВИ, хронической герпетической инфекции фациальной или генитальной
Goutières syndrome, familial chilblain lupus, spondyenchondromatosis, proteasome-associated autoinflammatory syndrome (PRAAS), Singleton-Merten syndrome), в результате которых возникает неадекватно высокая гиперпродукция ИФН I типа, сопровождающаяся определенным спектром клинических нарушений, называют интерферонопатиями I типа. Некоторые неврологические, сосудистые и кожные симптомы, характерные для интерферонопатий I типа при болезнях Менделя, присущи мультифакториальным болезням, таким, как системная красная волчанка (СКВ), системные васкулиты (СВ), аутоиммунные дерматомиозиты. Данные новых исследований позволяют лучше понять механизмы иммунопатогенеза этих аутоиммунных заболеваний, в основе которых также лежат интерферонопатии I типа. Прогресс в понимании механизмов иммунопатогенеза позволяет определить точные цели для разработки новых терапевтических стратегий. В тоже время, при таком первичном иммунодефиците, как синдром иммунной 
дисрегуляции, описана интерферонопатия, которая манифестирует высокими уровнями ИФН $\alpha$ на фоне дефицита регуляторных $\mathrm{T}$ лимфоцитов, аномального функционирования В клеток, дефектов «малых» нейтрофильных гранулоцитов (НГ) - НГ - низкой плотности, которые, характеризуются, повышенной способностью к неттинг- легко формируют нейтрофильные экстрацеллюлярные сети - NET, в результате чего образовавшиеся ДНК-комплексы провоцируют повышение синтеза ИФН преимущественно, при СКВ. Разработаны новые подходы к лечению тяжелой СКВ и других интерфернопатий I типа. Таргетная терапия моноклональными антителами в лечении интерферонопатий I типа при СKB: Sifalimumab, Rontalizumab против IFN $\alpha$, Anifrolumab против рецептора к ИФН $\alpha$ - IFN $\alpha$ R в настоящее время проходит 2 и 3 фазы клинических исследований. Обобщая представленные научные данные, можно заключить, что разработка и клинические исследования, проводимые по изучению
В первую очередь это связано с теми негативными эффектами, которые многие вирусы оказывают на систему интерферонов. Так, убедительно показано, что вирусы могут не только ускользать от воздействия ИФН, но и ингибировать действие ИФН, нарушать их продукцию посредством разнообразных механизмов. Многочисленными исследованиями продемонстрировано, что большое количество вирусов (все герпесвирусы, многие респираторные вирусы, вирусы хронического гепатита В и C, контагиозного моллюска, папилломы человека, том числе высокого онкогенного риска и т.д) продуцируют белки, способные ингибировать синтез и продукцию ИФН $\alpha / \beta$ и ИФНү. Описаны вторичные дефекты в системе ИФН у лиц, страдающих возвратными острыми респираторными инфекциями (ОРВИ) и различными хроническими, в т.ч. упорно-рецидивирующими герпесвирусными инфекциями. При этом иммунокомпрометированные дети разного возраста и взрослые субъекты могут страдать возвратными ОРВИ с частотой от 10 до 16-24 и более раз в год, что почти в $100 \%$ 


\begin{tabular}{|c|c|c|}
\hline $\begin{array}{l}\text { дисплазия } \\
\text { (SPENCD) }\end{array}$ & & $\begin{array}{lrr}\text { задержка } & \text { роста, } & \text { кальцификация } \\
\text { базальных } & \text { ганглиев } & \text { в веществе } \\
\text { головного } & \text { мозга, } \\
\text { тромбоцитопения, } & \text { артропатия, } \\
\begin{array}{l}\text { клеточного дефицит } \\
\text { иммунитета }\end{array} & \text { гу }\end{array}$ \\
\hline Дефицит ISG15 & ISG15 & $\begin{array}{l}\text { Кальцификация базальных ганглиев в } \\
\text { веществе головного мозга, судороги, } \\
\text { микобактериальные инфекции }\end{array}$ \\
\hline $\begin{array}{l}\text { Дефицит USP18 } \\
\text { (синдром } \\
\text { псевдо-TORCH) }\end{array}$ & USP18 & $\begin{array}{lcc}\begin{array}{l}\text { Кровоизлияние } \\
\text { кальцификация, } \\
\text { тромбоцитопения }\end{array} & \text { в } & \text { мозг } \\
\text { гепатомегалия, }\end{array}$ \\
\hline $\begin{array}{l}\text { Трихогепатоэнте } \\
\text { рический } \\
\text { синдром } 2\end{array}$ & SKIV2L & $\begin{array}{l}\text { Водянистая диарея, ломкие } \\
\text { спутанные волосы, повреждение } \\
\text { печени, умственная отсталость }\end{array}$ \\
\hline $\begin{array}{l}\text { Васкулопатия } \\
\text { сетчатки } \quad \mathrm{c} \\
\text { церебральной } \\
\text { лейкодистрофие } \\
\text { й (RVCL) }\end{array}$ & TREX1 & $\begin{array}{l}\text { Основные характеристики RVCL } \\
\text { включают начало среднего возраста, } \\
\text { прогрессирующую потерю зрения из- } \\
\text { за васкулопатии } \\
\text { (телеангиэктазии, микроаневризмы и } \\
\text { облитерации капилляров сетчатки } \\
\text { вокруг макулы) и различные } \\
\text { неврологические проявления, такие } \\
\text { как деменция или мигрень }\end{array}$ \\
\hline $\begin{array}{l}\text { Семейная } \\
\text { волчанка (FCL) }\end{array}$ & TREX1 & 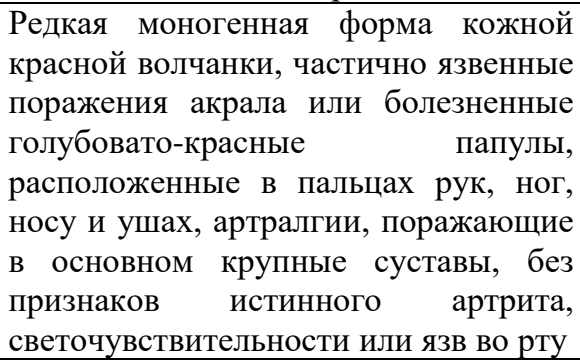 \\
\hline $\begin{array}{l}\text { X-сцепленное } \\
\text { сетчатое } \\
\text { пигментное } \\
\text { расстройство } \\
\text { (XLPDR) }\end{array}$ & POLA1 & 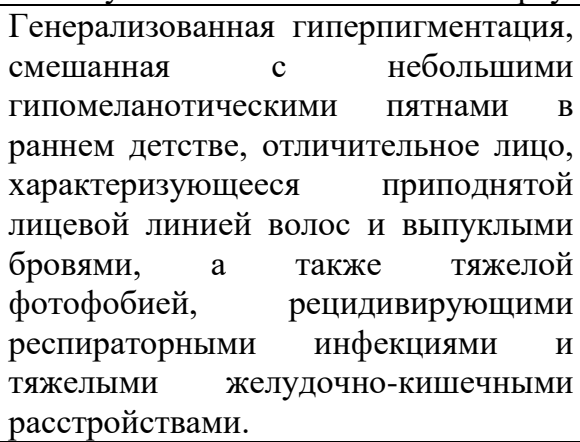 \\
\hline
\end{tabular}

эффективности и безопасности применения новых

биологических препаратов на основе монАТ, обладающих способностью нивелировать гиперпродукцию ИФН $\alpha$ при интерферонопатиях I типа, как при генетических болезнях Менделя, так и при таких аутоиммунных заболеваниях, как CКВ, CВ, открывают новые перспективы в лечении аутоиммунных процессов, сопровождающихся интерферонопатиями I типа.

Многочисленными исследованиями показано существование врожденных и приобретенных дефектов системы ИФН, ассоциированных с низким уровнем продукции ИФН. Врожденные дефекты ИФН I типа связаны с мутациями генов, ответственных за их синтез, что ведет к дефициту различных молекул, участвующих в активации генов, ответственных за синтез ИФН $\alpha / \beta$ (STAT1, UNC93B1, MCM4, TLR3, TRAF3, TRIF, TBK1) и низкому уровню ИФН $\alpha / \beta$. Описаны и уточнены дефицит ИФН $\gamma$, дефекты его рецептора IFNGR(ИФН- $\gamma \mathrm{R} 1)$ и дефицит ИЛ-12, играющего важнейшую роль в регуляции ИФН $\gamma$. Врожденные 
нарушения

системе

систематизированы в 2014г. и в 2015г в фундаментальной работе экспертов W.Al-Herz, A.Bousfiha, J.-L. Casanova et al. Доказано, что они ведут к возникновению тяжелой вирусной и бактериальной внутриклеточной инфекции, часто приводящей к летальному исходу. Таким пациентам показана заместительная терапия ИФН $\alpha 2 \mathrm{~b}$. Врожденный дефект рецептора ИФН внутриклеточными микобактериальными инфекциями.

Описаны также сочетанные генетические дефекты, связанные

с аутосомно-рецессивной мутацией гена STAT1, ведущие к дефициту ИФН $\alpha$ и ИФН $\gamma$ с проявлениями тяжелой вирусной и микобактериальной инфекций (Таблица 2).

Наряду с врожденными дефектами в системе ИФН, которые чаще всего ассоциированы с тяжелой вирусной инфекцией, существуют приобретенные дефекты в системе ИФН, которые могут возникать, как в детском возрасте, так и у взрослых субъектов.
Таблица 2. Генетические расстройства, связанные с ведущим нарушением иммунной системы и клиническими характеристиками интерферонопатий, связанных с избыточной экспрессией ИФН I типа.

\begin{tabular}{|c|c|c|}
\hline & & \\
\hline $\begin{array}{l}\text { Син } \\
\text { Айк } \\
\text { Гут }\end{array}$ & $\begin{array}{l}\text { TREX1 } \\
\text { RNASEH2B } \\
\text { RNASEH2C } \\
\text { RNASEH2A } \\
\text { SANHD } \\
\text { ADAR } \\
\text { IFIH1 }\end{array}$ & $\begin{array}{l}\text { Энцефалопатия, мышечная дистония, } \\
\text { микроцефалия, кальцификация } \\
\text { базальных ганглиев в веществе } \\
\text { головного мозга, судороги, } \\
\text { лихорадка, повышение уровня острой } \\
\text { фазы маркеров крови, цитопения, } \\
\text { повышение уровня интерферона в } \\
\text { спинномозговой жидкости }\end{array}$ \\
\hline $\begin{array}{l}\text { Син } \\
\text { Син } \\
\text { Мер }\end{array}$ & & $\begin{array}{lr}\text { Сердечно-сосудистые } & \text { заболевания с } \\
\text { кальцификацией } & \text { аорты, } \\
\text { остеопоретические } & \text { проявления, } \\
\text { аномалии зубов и скелет, } & \text { и сориатические поражения кожи }\end{array}$ \\
\hline $\begin{array}{l}\text { Хронический } \\
\text { атипичный } \\
\text { нейтрофильный } \\
\text { дерматоз с } \\
\text { липодистрофией } \\
\text { и повышенная } \\
\text { температура } \\
\text { (CANDALE) }\end{array}$ & $\begin{array}{l}\text { B4 } \\
\text { B3 } \\
\text { B8 } \\
\text { B9 } \\
\text { IP }\end{array}$ & 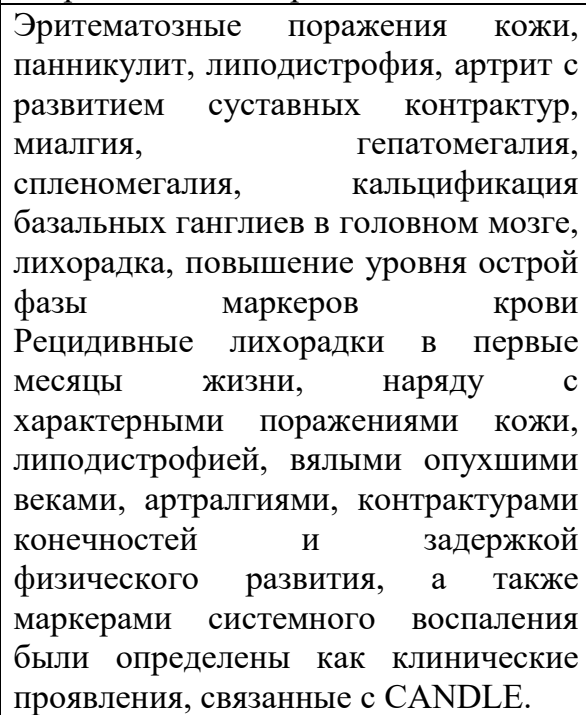 \\
\hline 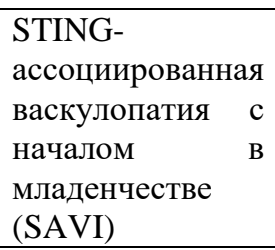 & 3 & 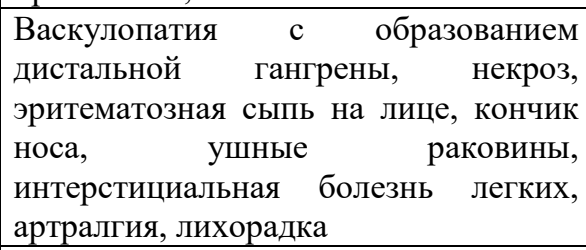 \\
\hline Спондилохондро & СP5 & Спондилометафизарная \\
\hline
\end{tabular}

